\title{
A MULHER COMO SUJEITO ATIVO NO CRIME DE ESTUPRO: CONSEQUENNCIAS CÍVEIS E PENAIS
}

THE WOMAN AS AN ACTIVE SUBJECT IN THE CRIME OF RAPE: CONSEQUENCES CIVIL LAW AND CRIMINAL LAW

Juliana Dos Santos MADURRO'

André Luis Jardini BARBOSA²

ISSUE DOI: $10.21207 / 2675-0104.2017 .680$

\begin{abstract}
RESUMO
Após a introdução da Lei n ${ }^{\circ} 12.015 / 2009$, que alterou o paradigma de proteção dos delitos de natureza patrimonial e passou a proteger não mais a mera liberdade, mas a dignidade sexual de homens e mulheres, o delito de estupro passou a ser doutrinariamente considerado como crime comum, ou seja, pode estar configurado sendo o homem ou a mulher sujeitos ativo ou passivo. Contudo, se por um lado pode-se afirmar ter ocorrido um imenso avanço no ordenamento jurídico penal brasileiro, deixando este de tutelar os costumes então vigentes na época da edição do Código Penal, por outro lado - e sem que os intérpretes da norma tenham se apercebido disso - houve o surgimento de outras questões relevantes, dentre as quais pode ser citada a possibilidade ou não de o homem, enquanto vítima, poder exigir do Poder Judiciário a interrupção de uma gravidez resultante da violência. A discussão é necessária e urgente, haja vista ter essa gravidez decorrido, também, de um ato delituoso, e repercute
\end{abstract}

\footnotetext{
${ }^{1}$ Discente da Faculdade de Direito de Franca/SP. Bolsista do Programa Interno de Iniciação Cientítica (PIBIC 2017-2018).

${ }^{2}$ Possui graduação em Direito pela Universidade Estadual Paulista Júlio de Mesquita Filho (1993) e mestrado em Direito das Relações Econômico Empresariais pela Universidade de Franca (2003). Atuou como professor titular da Universidade de Franca - UNIFRAN, até junho de 2008. Atualmente execer a docencia junto ao Centro Univesitário da Fundação Educacional Guaxupé-MG e na Faculdade Dr. Francsico Maeda- FAFRAM, em Ituverava-SP. Presta Serviços como Professor Colaborador da Faculdade de Direito de Franca-SP. Tem experiência na área de Direito Público, com ênfase em Direito Penal e Direito Processual Penal.
} 
para além do âmbito penal, atingindo, inclusive, questões relativas ao dever do pai em reconhecer ou não o fruto da gestação, prestar ou não os alimentos à criança nascida de uma situação de violência, dentre outros. A análise do presente tema não tem, por óbvio, a intenção de esgotar o tema, mas despertar a reflexão no sentido de alcançar novas situações até então desconhecidas para o Direito, mas extremamente presentes no cotidiano das relações sociais.

Palavras-Chave: Estupro. Vitima homem. Mulher agressora. Consequências cíveis. Consequências penais.

\begin{abstract}
Following the introduction of Law No. 12.015 / 2009, which changed the paradigm of protection of offenses of a patrimonial nature and no longer protected mere freedom, but the sexual dignity of men and women, the crime of rape became doctrinally considered as common crime, that is, can be configured being the man or woman subject active or passive. However, if on the one hand it can be said that there has been a huge advance in the Brazilian criminal legal system, which no longer protects the customs then in force at the time of the edition of the Penal Code, on the other hand - and without the interpreters of the norm having aware of this - other relevant issues have arisen, including the possibility of whether or not a man, as a victim, may require the Judiciary to terminate a pregnancy resulting from violence. The discussion is necessary and urgent, given that this pregnancy was also the result of a criminal act, and has repercussions beyond the criminal sphere, including issues related to the father's duty to recognize or not the fruit of pregnancy, to provide or not food to the child born of a situation of violence, among others. Obviously, the analysis of the present theme is not intended to exhaust the theme, but rather to arouse reflection in order to reach new situations hitherto unknown to law, but extremely present in the daily life of social relations.
\end{abstract}

Keywords: Rape. Victim man. Aggressive woman. Civil consequences. Criminal Consequences.

O surgimento de uma nova lei ou a sua alteração, decorrem das necessidades dos entes integrantes do corpo social no qual ela se encontra inserida. Isso porque, como se sabe, as leis buscam sempre reproduzir os anseios da sociedade, destinando-se a reger a vida dos indivíduos.

O mesmo se deu para com a Lei $n^{\circ} 12.015 / 2009$, a qual fez espelhar a assimilação de costumes diferenciados para com os das gerações passadas, sendo exigida a adequação do texto para com as novas conceituações de Liberdade e Dignidade Sexual.

A próxima mudança é em relação à junção em um mesmo tipo penal os antigos crimes de "estupro" e "atentado violento ao pudor". Então, a partir do momento em que a lei entrou em vigor, quaisquer atos libidinosos praticados contra "alguém" - já não mais fazendo distinção entre homens e mulheres - mediante violência ou grave ameaça, passaram a configurar a nova figura penal do estupro.

No escopo do texto da lei passada, ainda havia muitas dúvidas em relação à tipificação da conduta da mulher que constrangesse o homem 
a com ela ter conjunção carnal (penetração do pênis na vagina), já que, até aquele momento, o crime de estupro se traduzia no ato de "constranger mulher a conjunção carnal mediante violência ou grave ameaça". Assim, a mulher nunca poderia ser sujeito ativo em um crime de estupro, somente podendo atuar como coautora ou participe.

Com isso, é apontado mais uma mudança significativa, no referido delito, que deixa de ser crime próprio (exigência de um especifico sujeito ativo), ou seja, somente o homem poderia cometer tal núcleo do tipo, passando agora ser crime comum, motivo pelo qual, não há mais a distinção de gênero, podendo este, portanto configurar tanto como sujeito ativo quanto passivo.

Com tais mudanças, houve uma alteração substancial no crime de estupro, relevante para o nosso sistema penal.

Esse fato foi um grande avanço em relação a adequar a lei à necessidade da sociedade, porém, nem todas as discussões foram resolvidas.

Quando o legislador pensou por um lado, em dar às pessoas o livre dispor de suas liberdades sexuais, acabou por deixar lacunas nas leis em relação às consequências jurídicas da mulher quando configurar como sujeito ativo no crime de estupro.

São problemas que devem ser pensados, debatidos e resolvidos, sobretudo quando considerada a questão histórica da luta das mulheres pela igualdade de gênero, a qual passa, também, pela análise de uma eventual gravidez decorrente da violência daquela em relação ao homem, além das discussões civis relativas à paternidade indesejada do produto da concepção criminosa.

Neste trabalho também serão abordadas as consequências na área penal, com relação à causa de aumento de pena, que tenha como resultado a gravidez e a mulher autora do crime e, no caso do aborto sentimental, se poderá ser requisitado pela vítima homem ou pela mulher agressora.

Esses e outros casos relacionados serão discutidos, nesse referido trabalho, sob o ângulo de diversos ramos do Direito, a fim de se chegar a uma solução plausível a respeito dos casos em que a lei silenciou. 


\section{O DELITO DE ESTUPRO E A SUA NOVA CONFORMAÇÃO}

Entende-se por estupro a conduta por meio da qual o agressor, com emprego de violência ou grave ameaça, constrange a própria vítima ou até mesmo terceira pessoa - para que ela pratique com ele conjunção carnal ou qualquer outro ato libidinoso, para satisfazer sua lascívia, ou a de outrem. Tem-se pois, ser o núcleo do tipo penal o efetivo constrangimento da vítima.

Para a configuração do crime, o ato deverá contem um dos dois tipos de constrangimento sexual para com a vítima, sendo eles: a conjunção carnal ou quaisquer outros atos libidinosos.

Por conjunção carnal entende-se por coito vagínico, compreendido como a introdução completa, ou não, do pênis do agente na vagina da vítima, sendo indiferente a questão da ejaculação ${ }^{3}$.

Por ato libidinoso há a compreensão da manifestação física do instinto sexual, expressa como todas as formas de contatos físicos que podem explicitar a libido, como por exemplo, apalpar partes íntimas, sucção nos seios, coito oral e anal, introduzir objetos nas partes íntimas, dentre outros.

A consumação dar-se-á imediatamente após a prática de qualquer ato libidinoso, por meio do qual ocorra o contato corporal, ou a conjunção carnal.

Frisa-se que, por mais que aconteçam atos libidinosos diversos à conjunção carnal, antes daquela propriamente dita, a doutrina e a jurisprudência majoritárias têm se inclinado no sentido de que o agente será punido como um único ato no crime de estupro, pois, os atos preparatórios serão absolvidos pela conjunção carnal, devido ao fato desta se tratar de ato mais gravoso.

Por outro lado, uma vez que o estupro é crime que tem por objetivo a satisfação da lascívia do próprio agente ou de outrem, uma vez satisfeita aquela pulsão sexual, a prática de novas conjunções carnais por parte do agente, irá ocorrer a configuração de um novo crime de estupro,

\footnotetext{
${ }^{3}$ Muito embora não seja esse o tema do presente artigo, fato é que a ejaculação tem sido entendida como uma mera manifestação decorrente da manipulação do órgão genital, podendo ocorrer ainda que se esteja diante de casos de violência. A esse respeito, serão tecidas maiores considerações mais à frente.
} 
e, por conseguinte, a soma das penas, em virtude da aplicação da regra do concurso material de crimes.

Para a execução do crime, o autor irá utilizar-se de meios violentos ou de grave ameaça, com a finalidade de constranger sexualmente sua vítima.

Tal delito está caracterizado, como elemento subjetivo, o dolo específico do autor, pois, este já tem por finalidade a satisfação de sua lascívia sem o consentimento da vítima. Sendo assim, por óbvio, não se aceita a modalidade culposa.

A tentativa é possível, nos casos em que o autor do crime, antes de iniciadas as manobras sexuais, seja interrompido por algo externo, alheio a sua vontade.

A ação penal será pública condicionada a representação da vítima ou de seu sucessor, conforme consta no artigo 225 do Código Penal. Contudo, há a ressalva, nos casos em que a vítima seja menor de 18 anos e maior que 14 anos ou caso a conduta resulte em lesão grave ou morta, a ação passará a ser pública incondicionada, em consonante ao mesmo artigo.

Este delito trata-se de crime hediondo, devido ao fato, de estar previsto no artigo $1^{\circ}$ da Lei 8.072/90, nos incisos V e VI.

Em relação aos sujeitos desta norma incriminadora o Código Penal Brasileiro de 90, em seu artigo 213, descrevia sobre o antigo delito do estupro, trazendo em sua letra de lei a palavra mulher, demonstrando que, somente esta poderia configurar como vítima, motivo pelo qual, podese dizer que tal lei pertencia a um rol taxativo.

Com isso, havia a ocorrência do engessamento do sujeito passivo, tendo como consequência a não abertura para interpretação diversa, considerando que a única possibilidade de a mulher ser o sujeito ativo, na antiga lei, era como coautora em conjunto com algum homem para constranger a vítima.

Após, o advento da Lei 12.015/2009, ocorreram mudanças significativas, com relação aos sujeitos da atual norma incriminadora do delito de estupro.

Como destaque, deve-se mencionar a substituição da palavra "mulher" pela expressão genérica "alguém", podendo então, a partir deste fato, qualquer pessoa configurar como sujeito passivo, ou como autor, não 
se exigindo mais, nenhuma característica especifica, tornando-se, portanto, crime comum.

A esse respeito, comporta menção a doutrina de Guilherme de Souza Nucci:

O sujeito ativo pode ser qualquer pessoa do mesmo modo que o sujeito passivo. A alteração provocada pela Lei 12.015/2009 transformou o delito de estupro em crime comum. Há variadas formas de realização e envolvidos no delito podem ser Homemmulher, Mulher- Homem, Homem-Homem, Mulher-Mulher, enfim, qualquer contato libidinoso entre pessoas humanas. Assim sendo, deixa-se de se falar em crime próprio ${ }^{4}$.

\section{Com relação ao sujeito passivo, leciona Fabio Agne Fayet:}

Em razão disso, há autores que entendem ser sujeito passivo a pessoa humana, qualquer que seja sua condição ou opção sexual, não tendo mais relevância jurídica penal a conceituação de coito vaginal, e, portanto, a diversidade de gêneros. Isso porque, a partir da nova legislação não mais diferenciam os gêneros para a proteção da dignidade sexual, podendo, inclusive, dar ensejo ao estupro bilateral $^{5}$.

Há pessoas que acreditam que, se o homem tiver ereção estará consentindo com o ato, mas, isso não passa de um mero pensamento decorrente, em grande medida, da orientação machista da sociedade, uma vez que, em grande parte das vezes, o órgão genital masculino acabará por atingir a ereção sem que o homem ao menos deseje isso. É o que acontece, por exemplo, nos casos em que a pessoa esteja dormindo, como nos ensina Guilherme de Souza Nucci:

Há os que duvidam dessa situação, alegando ser impossível que a mulher constranja o homem à conjunção carnal. Abstraída a posição nitidamente machista, em outros países, que há muito convivem com o estupro de forma como hoje temos no Código Penal, existem vários registros a esse respeito. Alguns chegam a mencionar ser crime impossível, pois, se o homem for ameaçado, não seria capaz de obter a ereção necessária para a conjunção carnal. Ora, há vários tipos de ameaça grave, não necessariamente exercida com emprego de armas no local do delito. Ademais, existem inúmeros medicamentos dispostos a fomentar a ereção masculina na atualidade. E por derradeiro, quem está ameaçado pode, perfeitamente, fazer valer a sua lascívia, que depende

\footnotetext{
${ }^{4}$ NUCCI, Guilherme de Souza. Curso de direito penal. Curso de direito penal. parte especial: arts. 213 a 361, do Código Penal. Rio de Janeiro: Forense, 2017. p. 80.

${ }^{5}$ FAYET, Fabio Agne. O delito de estupro. Porto Alegre: Livraria do Advogado, 2011. p. 53-54.
} 
unicamente de um comando mental. No mais, ainda que se possa dizer rara a hipótese, está bem distante de ser impossível. Além disso, qualquer toque lascivo da mulher no corpo do homem, valendo-se de violência ou grave ameaça, hoje, também é capaz de configurar o estupro, independentemente da copula carnal ${ }^{6}$.

Com isso, não restam dúvidas de que as mudanças ocorridas na Lei 12.015/2009 fizeram com que o estupro se tornasse comum, podendo, assim, ser praticado tanto pelo homem como pela mulher, numa aplicação plena da igualdade de gênero na prática deste delito tão grave.

\section{3 \\ AS QUESTÕES DA MAJORAÇÃO DA PENA E A INTERRUPÇÃO DA GRAVIDEZ QUANDO RESULTANTES DE ESTUPRO TENDO COMO SUJEITO ATIVO A MULHER}

Estabelecida à premissa de que a nova legislação estabeleceu a dignidade sexual como o seu âmbito de proteção, não mais se exigindo do sujeito ativo características específicas, surge a necessidade de analisar-se a questão da eventual gravidez decorrente de estupro quando for o homem a vítima do delito e a mulher a sua autora.

Essa discussão é relevante, na medida em que traz consigo gravíssimas consequências seja em âmbito civil ou penal.

A primeira questão que deve ser debatia, é no que concerne ao aumento de pena previsto no artigo 234-A, III. do Código Penal Brasileiro, a saber, a questão da majoração de pena nos casos em que o delito resultar em gravidez, questionando, se deverá ou não, ser aplicada também, quando a mulher for a agressora no delito de estupro e não mais vítima, uma vez que, tal lei não especifica o gênero dos sujeitos que poderão ser aplicados o aumento de pena.

$\mathrm{Na}$ mesma linha de raciocínio, na esfera criminal, tem-se o assunto do aborto sentimental, que seria o aborto permitido pela lei 128, II do Código Penal Brasileiro, nos casos em que a vítima engravide em decorrência da conduta delitiva do crime de estupro.

\footnotetext{
${ }^{6}$ NUCCI, Guilherme de Souza. Curso de direito penal. Curso de direito penal. parte especial: arts. 213 a 361, do Código Penal. Rio de Janeiro: Forense, 2017. p. 80.
} 
Assim, tal permissão poderá abranger ou não a mulher agressora, posto que, a letra da lei, não específica à posição que esta deva estar no crime de estupro (vítima ou agressora).

Para resposta devemos analisar a razão de ser da majoração da pena.

Quando se fala, no caso de aumento de pena em que o crime resulte gravidez, previsto no artigo 234-A, III, do Código Penal Brasileiro, percebe-se que, o legislador, preocupou-se em agravar a pena do agente, pelo motivo da vítima ter o ônus de suportar sozinha o resultado da conduta.

A esse respeito, deve ser conferida a lição de Guilherme de Souza Nucci: "Imagina- se a preocupação do legislador quando se vislumbra a prática de um estupro entre pessoas estranhas, com resultado gravidez. A gestante terá que passar pela grave decisão de abortar ou não (art. 128, II, CP)",7.

Como conclusão, se o objetivo da majoração da pena, apontada anteriormente, é pelo fato da vítima ter que suportar o ônus do resultado da agressão, tal situação, não poderá ser pensada de forma distinta, quando o homem for vitimado, pois, este também, suporta os prejuízos da agressão, como por exemplo, questão financeira (pelos direitos sucessórios, pagamento de pensão alimentícia), e emocional (o dilema do filho fora do casamento, de ter que conviver com a agressora se desejar ter afetividade com a criança gerada).

Assim, deverá aplicar o caso de aumento de pena (art.234-A, III), similarmente a mulher agressora, devido ao fato, que o homem vítima também suporta consequências gravosas decorrentes do delito.

Em relação ao aborto este, é permitido na legislação atual brasileira somente em dois casos, mencionados no artigo 128 do Código Penal. No inciso I, tem-se o aborto terapêutico ou necessário, que é aquele realizado para salvar a vida da gestante, e no inciso II, o denominado aborto sentimental, humanitário ou ético, que são os casos que tenham como resultado de um crime de estupro a gravidez, e a vítima deseja interrompela. Isso ocorre pelo fato de não a obrigar a ter que conviver com o fruto da agressão.

\footnotetext{
${ }^{7}$ NUCCI, Guilherme De Souza. Crimes contra a dignidade sexual: Comentários à Lei 12.015, de 7 de agosto de 2009. São Paulo: Saraiva, 2009. p. 97.
} 
A questão, não poderá ser interpretada de forma igualitária ao homem vitimado, pois, na lei, vem expressa a necessidade do consentimento da gestante, ou de seu representante legal, logo, o homem, nunca poderá fazer jus à solicitação do aborto permitido, devido ao fato, que não há nenhuma lei, até hoje, que permita tal situação.

Por outro lado, deve ser questionado, se a agressora poderá valerse do aborto sentimental (artigo 128, II), já que possui os requisitos da norma, que seriam: a gravidez resultada pelo crime de estupro e o consentimento da gestante para tal ato.

Este questionamento tem como resposta negativa, não podendo aquela fazer jus ao direito do aborto sentimental.

Em razão de que, a atual Constituição Federal Brasileira, garante a proteção da vida uterina, não devendo transmitir ao feto as consequências de sua genitora por ter praticado a agressão.

A esse respeito, ensina Eduardo Luiz Santos Cabette:

\begin{abstract}
Não se pode compreender como um capricho criminoso que ensejou um coito desejado pela mulher poderia dar lugar a outro capricho, agora abrigado pela lei, em eliminar a vida intrauterina. Isso seria o cúmulo da banalização do desprezo pela vida humana em sua fase inicial ${ }^{8}$.
\end{abstract}

A título de conclusão, tem-se que a mulher agressora não terá direito ao aborto permitido, uma vez que sua dignidade não foi, em momento algum, violada, não podendo ocorrer à inversão de valores, de modo a desvalorizar a vida do feto.

Adentrando na esfera civil, com o nascimento do fruto da concepção violenta, tal situação trará tanto para o infante quanto para o homem vítima consequências jurídicas extremamente relevantes, como, por exemplo, o direito ao reconhecimento da paternidade, pagamento de pensão alimentícia, direitos sucessórios, dentre outras.

Com isso, nos deparamos com dois princípios que estão em conflitos que seriam: o princípio da dignidade da vida do infante, envolvendo o direito aos alimentos, sucessões, registro, sobrenome dos genitores, guarda, visita, dentre outros e, em contrapartida, e o princípio da proteção da integridade física e psíquica da vítima, pois, este tem que

\footnotetext{
${ }^{8}$ CABETTE, Eduardo Luiz Santos. Crimes contra a dignidade sexual: temas relevantes. Curitiba: Juruá, 2010. p. 139.
} 
suportar os efeitos da paternidade, sendo ele, obrigações financeiras e afetivas para com a criança.

A esse respeito, leciona Humberto Bergmann Ávila explica que deve ocorrer à ponderação aos princípios fundamentais conflitantes, para ver quais os quesitos devam prevalecer sob o outro. Ressalta-se que, esta ocorrência não afirma a retirada do direito fundamental de uma pessoa, para acrescentar ao outro, e sim, ponderar o mais relevante para a garantia da dignidade da pessoa humana ${ }^{9}$.

Por óbvio que o direito a vida da criança sobrepõe o direito de proteção da integridade física e psíquica da vítima. Ou, como prefere Flavio Tartuce: "No plano conceitual e em sentido amplo, os alimentos devem compreender as necessidades vitais da pessoa, cujo objetivo é a manutenção da sua dignidade: a alimentação, a saúde, a moradia, o vestuário, o lazer, a educação, entre outros" "10.

Sendo assim, a criança terá direito aos alimentos, em pleitear na justiça o reconhecimento da paternidade, caso o genitor não venha a registrar, participar da sucessão, dentre outro direitos amparados pelo ordenamento civil.

Por fim, não deve confundir a conduta que a genitora do menor teve, com os direitos que a criança possui, uma vez que, este não teve culpa do ocorrido e não poderá ser penalizado.

Para compensar os resultados desfavoráveis advindo do constrangimento, e pela violência que a vítima sofreu esta, não poderá ficar desamparada juridicamente na esfera civil, tendo o direito de ressarcimento pelos danos sofrido.

Como solução intermediária, o instrumento processual que poderá amparar a vítima é a ação civil "ex delicto", que tem por finalidade, conforme atenta Fernando da Costa Tourinho Filho ${ }^{11}$, após, uma sentença transitada em julgado na esfera criminal, dar o direito vítima em propor ação de indenização com a finalidade de reparação pelos danos sofridos em decorrência do crime.

\footnotetext{
9 ÁVILA, Humberto Bergmann. Teoria dos princípios: da definição à aplicação dos princípios jurídicos. 3 ed. São Paulo: Malheiros, 2004. p. 30.

${ }^{10}$ TARTUCE, Flávio. Direito civil, v. 5: Direito de Família. 12 ed. Rio de Janeiro: Florence, 2017. p. 317.

${ }^{11}$ TOURINHO FILHO, Fernando Da Costa. Manual de processo penal. 16 ed. São Paulo: Saraiva, 2013.
} 
Pode-se encontra o fundamento legal para este tipo de ação, no Código Civil em seus artigos 186 e 927; no Código Penal, em seu artigo 91, inciso I; e no Código de Processo Penal, em seu artigo 63, dando direito a vítima do delito, em ingressar judicialmente, objetivando os danos causados pelo seu agressor.

Ao longo do trabalho, foi demonstrado a possibilidade jurídica de a mulher constranger o homem para que com ela mantenha conjunção carnal. Contudo, poucos são os casos divulgados ou até mesmo denunciados.

Isso ocorre, pois, a sociedade Brasileira, ainda pode ser considerada machista com relação a este assunto, acreditando, algumas pessoas, em que o homem não poderá ser estuprado por uma mulher, em situações de fato, não passando tudo isso de uma teoria criada pela Lei Penal.

O motivo de não acreditarem é pela existência de uma imposição da sociedade para com os homens, de que estes têm a obrigação de manter relação sexual com uma mulher.

Assim, na maioria das vezes, as vítimas nem percebem a gravidade do fato, em que estão sendo persuadidos a manter conjunção carnal com alguém ou praticar qualquer ato libidinoso sem a sua vontade.

Ou até mesmo, os que sabem que foram estuprados, mas, não possuem a coragem de denunciar, preocupando-se com que as outras pessoas vão pensar.

\section{CONSIDERAÇÕES FINAIS}

Diante dos argumentos expostos ao longo do trabalho, como conclusão, pode se dar a possibilidade jurídica da mulher configurar como autora no crime de estupro em decorrência da introdução da Lei 12.015/2009 que modificou o referido delito, tornando-o crime comum.

As mudanças procedidas trouxeram consigo situações não explicadas de forma clara pelo ordenamento jurídico brasileiro para os casos em que seja a mulher o sujeito ativo do delito de natureza sexual e o homem o seu sujeito passivo.

Existem consequências cíveis e penais graves e extremamente relevantes, como se pode perceber. 
Destas consequências, há o entendimento que deverá ser aplicada a majoração da pena, prevista no artigo 234-A, inciso III, também, para a mulher agressora, pois, a finalidade desta norma, é a penalização maior do agressor, que causou violência para com a vítima, deixando-a com encargos decorrestes da gravidez.

Em continuação, foi apontado o caso do aborto sentimental, previsto no artigo 128, inciso II do Código Penal Brasileiro.

Este tipo não poderá ser abrangido tanto pela mulher agressora quanto pelo homem vítima. Isso se dá, pelo motivo, da não banalização da vida intrauterina, não podendo transmitir a criança as consequências de sua genitora, autora do crime de estupro.

E tratando-se da vítima homem, este não está amparado por nenhuma lei brasileira, que conceda o aborto permitido.

$\mathrm{Na}$ esfera civil, ocorre a prevalência das obrigações alimentares, para com a criança, a serem exercidas pelo seu genitor. Isso ocorre, pois, as obrigações paternas são para a garantia da dignidade a vida do infante.

No entanto, em contrapartida, pode ser entendida, solução intermediária, para suprir a vítima homem, dos danos decorrentes da infração, sendo ela a postulação da ação civil ex delicto, com o objetivo de indenização dos danos causados pelo crime a serem pagos pelo agente causador.

Ao final foi ressaltado que a sociedade brasileira ainda é considerada machista em não aceitar que o homem possa ser estuprado por uma mulher.

Como explicação desta situação, as pessoas tendem a ter o pensamento de que o homem é obrigado em manter relação sexual com a mulher, mesmo contra a sua vontade.

Por este motivo, há poucos casos denunciados ou até mesmo a vítima não compreende a gravidade da situação e, por vezes, nem mesmo consegue entender que foi estuprada.

\section{REFERÊNCIAS BIBLIOGRÁFICAS}

ÁVILA, Humberto Bergmann. Teoria dos princípios: da definição à aplicação dos princípios jurídicos. 3 ed. São Paulo: Malheiros, 2004. 
BITENCOURT, Cezar Roberto. Tratado de direito penal, v. 4: parte especial - dos crimes contra a dignidade sexual até dos crimes contra a fé pública. 9 ed. São Paulo: Saraiva, 2015.

CABETTE, Eduardo Luiz Santos. Crimes contra a dignidade sexual: temas relevantes. Curitiba: Juruá, 2010.

CAPEZ, Fernando. Curso de direito penal. 10 ed. São Paulo: Saraiva, 2012.

COSTA, FERNANDO JOSÉ DA. Código penal comentado. 10 ed. São Paulo: Saraiva, 2013.

ESTEFAM, André. Crimes sexuais: Comentários à Lei 12.015/2009. 1 ed. São Paulo: Saraiva, 2009.

FAYET, Fabio Agne. O delito de estupro. Porto Alegre: Livraria do Advogado, 2011.

FÜHRER, Maximiliano Roberto Ernesto. Novos crimes sexuais: com a feição instituída pela lei 12.015, de 7 de agosto de 2009. São Paulo: Malheiros Editora LTDA, 2009. 232 p.

GRECO, Rogério. Curso de direito penal: parte especial. 14 ed. Niterói: Impetus Ltda, 2017.

JESUS, DAMÁSIO DE. Direito penal: parte especial. 23 ed. São Paulo: Saraiva, 2015.

MARCÃO, RENATO; GENTIL, Plínio. Crimes contra a dignidade sexual: Comentários ao Titulo VI do Código Penal. 2 ed. São Paulo: Saraiva, 2015.

NUCCI, Guilherme De Souza. Crimes contra a dignidade sexual: Comentários à Lei 12.015, de 7 de agosto de 2009. São Paulo: Saraiva, 2009.

NUCCI, Guilherme de Souza Curso de direito penal: parte especial : arts. 213 a 361 do código penal. Rio de Janeiro: Forense, 2017.

TARTUCE, Flávio. Direito civil, v. 5: Direito de Família. 12 ed. Rio de Janeiro: Florence, 2017.

TOURINHO FILHO, Fernando Da Costa. Manual de processo penal. 16 ed. São Paulo: Saraiva, 2013. 